\title{
Patrimonio, terrorismo y desastres naturales ¿Cómo prevenir y abordar los enormes daños al patrimonio cultural mundial? Una visión desde la UNESCO
}

Francisco Javier López Morales | Instituto Nacional de Antropología e Historia (INAH, México)

Francisco Vidargas | miembro del Consejo Internacional de Monumentos y Sitios (ICOMOS)

URL de la contribución <www.iaph.es/revistaph/index.php/revistaph/article/view/4129>

"Una de las maneras de deshacerse de la historia es eliminar todos los rastros físicos de esa historia. Fingir que nada hubiera pasado, que nunca hubo nada ahí".

Daniel Libeskind

\section{Patrimonio en zonas de conflicto}

Meses atrás tuvimos la oportunidad de participar en una mesa de discusión-conversación organizada por el Comité mexicano del Consejo Internacional de Museos (ICOM), que tuvo como tema central la proyección del documental La destrucción de la Memoria-2016 (The Destruction of Memory, film dirigido por el cineasta australiano Tim Slade quien se basó en el libro The destruction of memory, del escritor y periodista Robert Bevan, publicado en el año 2006) y justo ahora consideramos relevante compartir algunos puntos que formaron parte central de esa discusión.

Es innegable llegar a pensar que en las últimas guerras no se destruyen los edificios porque estén en el trayecto de un objetivo específico, sino que son los edificios mismos los que son el dicho objetivo.

Robert Bevan, autor del libro citado (2006), lo precisa en este sentido:

$>$ Los edificios son parte de quienes son. La destrucción de bienes culturales es parte de una estrategia consciente e intencionada para atacar y destruir la memoria colectiva, la historia y la identidad de un pueblo, así como la manera en la que vemos el desarrollo y la evolución de la civilización humana.

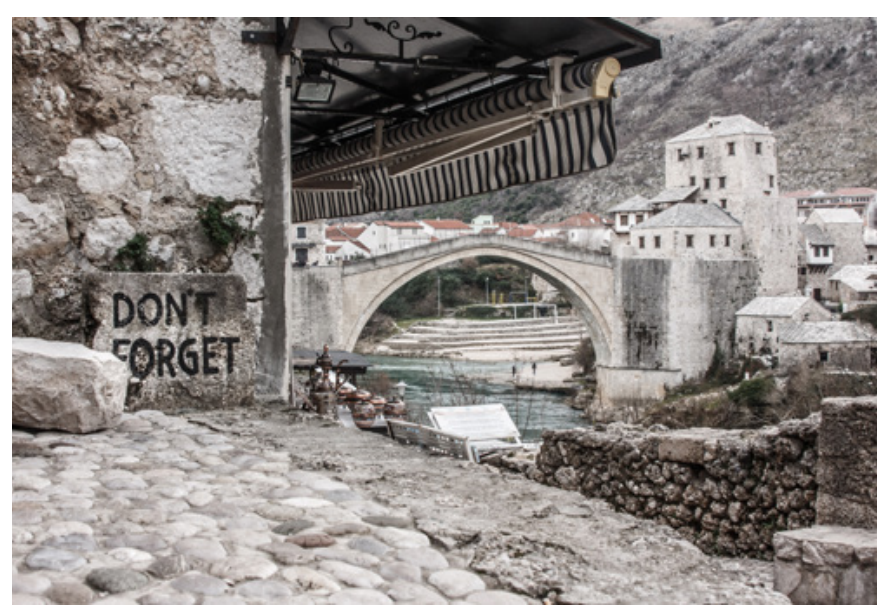

Puente de Mostar tras su reconstrucción | foto Omer Tarik Koc

> La remoción de las huellas físicas de la historia es la aniquilación del patrimonio cultural; el daño no es sólo a un monumento, un edificio, una ciudad, un pueblo o localidad, sino a la historia y cultura de la humanidad. La destrucción de la cultura es un arma de guerra, utilizada para matar la identidad de otros: la memoria, lo que han hecho y edificado, todo lo que han anhelado, trabajado y conseguido.

$>$ Los monumentos que lograron sobrevivir a los estragos del medio ambiente y a los desastres naturales ahora sucumben a estrategias militares.

Los conflictos bélicos en diversos países y épocas han dejado grandes daños directos y colaterales a sitios y monumentos históricos, como el atroz genocidio de la guerra de los Balcanes, que destruyó en 1991, mediante centenares de obuses, parte de la ciudad vieja 
_a debate Patrimonio, terrorismo y desastres naturales ¿Cómo prevenir y abordar los enormes daños al patrimonio cultural mundial?

| coordinan Francisco Javier López Morales, Francisco Vidargas

de Dubrovnik, la antigua capital dálmata de Ragusa, a los pies del mar Adriático y que en 1979 fue declarada patrimonio mundial (con ampliación en 1994), como la otomana Sarajevo, capital nacional de Bosnia y Herzegovina, rica en diversidad religiosa y por lo mismo, la ciudad que sufrió el mayor asedio y destrucción durante la guerra regional. Las imágenes del incendio que destruyó su Biblioteca Nacional (Vijećnica) nunca serán olvidadas.

Asimismo, la destrucción de mezquitas e iglesias católicas, así como del patrimonio ortodoxo, fueron parte de los ataques serbios en la comunidad de Visegrad (Višegrad) y Vlasenica, República Srpska Bosnia y Herzegovina. Excepcional es el caso del pueblo de Baljvine, en el que por fortuna fueron respetadas sus diferencias religiosas, al igual que el valor cultural de sus monumentos, lo que permitió la conservación de la única mezquita que mantiene su minarete, entre 600 que fueron destruidas en el conflicto bélico.

El Consejo ejecutivo de la UNESCO, después de manifestar su preocupación por "las continuas matanzas y agresiones de que son víctimas seres humanos inocentes y por la destrucción del patrimonio cultural y arquitectónico de Bosnia y Herzegovina como consecuencia de la política de depuración étnica y cultural", pidió al Director General que preparara, en coordinación con las autoridades de Bosnia y Herzegovina, además de la participación de otras organizaciones internacionales, regionales, intergubernamentales y no gubernamentales, "proyectos de restauración y reconstrucción en el marco del plan general en el que se prestará la debida atención al carácter multicultural y multirreligioso del país" (144 EX/34).

Asimismo solicitó que se preparara un "proyecto piloto para Móstar en el marco del plan general de restauración y reconstrucción del patrimonio cultural bosnio, mediante la creación de un comité compuesto por expertos de Bosnia y Herzegovina y funcionarios responsables de la Secretaría, así como por expertos de los Estados Miembros que deseen participar [que pre-

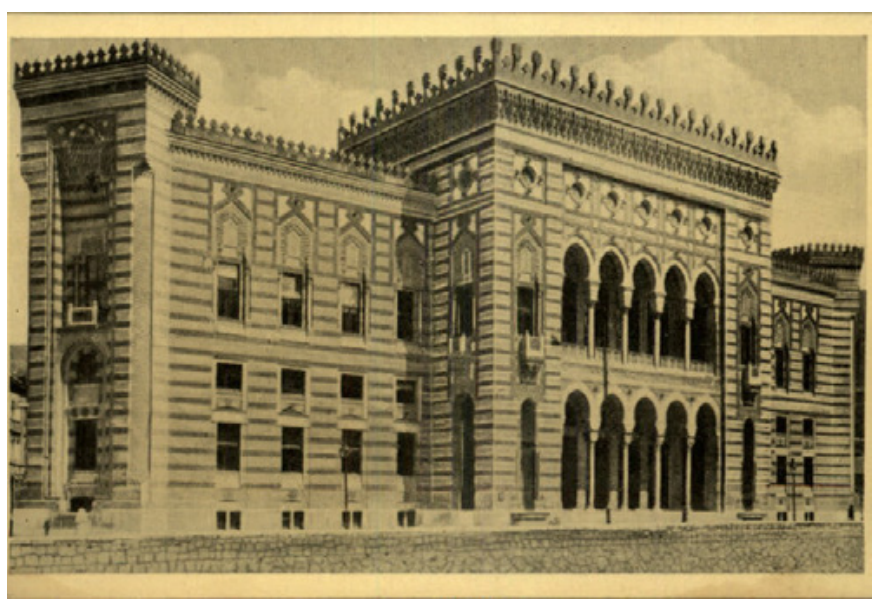

El Ayuntamiento de Sarajevo, conocido como Vijećnica, en 1941. El edificio fue destruido durante la guerra en 1992 | foto Smooth O

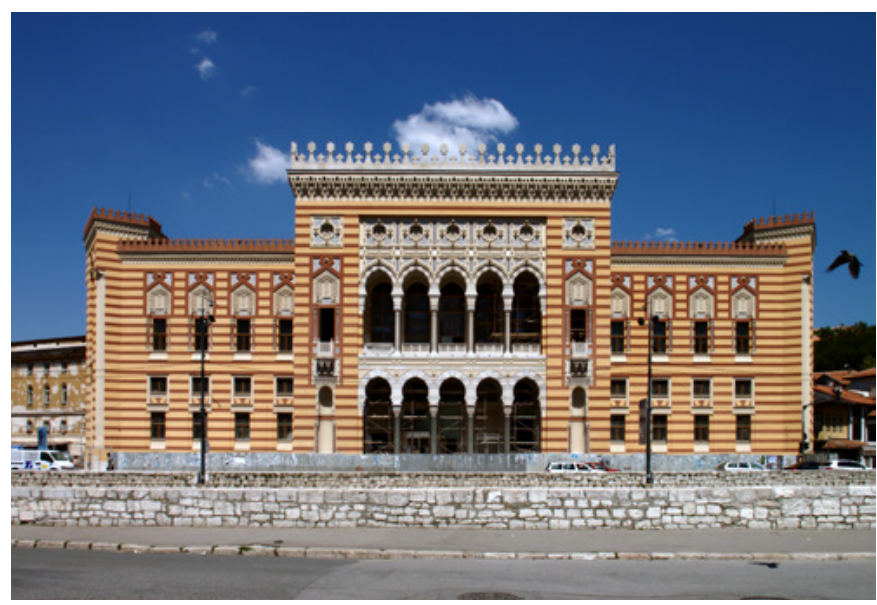

Casi terminada la reconstrucción del edificio del Ayuntamiento como Biblioteca Nacional de Sarajevo | foto Aktron

pare] proyectos concretos para cada edificio o conjunto de edificios históricos y arquitectónicos (mezquitas, iglesias, sinagogas, puentes, baños, bazares, etc.); y, tomando como ejemplo el proyecto de reconstrucción del puente de Móstar, pida colaboración bilateral o multilateral" (144 Ex/34).

Koichiro Matsuura, en ese momento Director General de la UNESCO, advirtió que la presencia del organismo internacional de las Naciones Unidas en Móstar obedecía "al propósito de insuflar de nuevo vida a un patri- 


\begin{abstract}
a debate Patrimonio, terrorismo y desastres naturales ¿Cómo prevenir y abordar los enormes daños al patrimonio cultural mundial?
\end{abstract}

| coordinan Francisco Javier López Morales, Francisco Vidargas

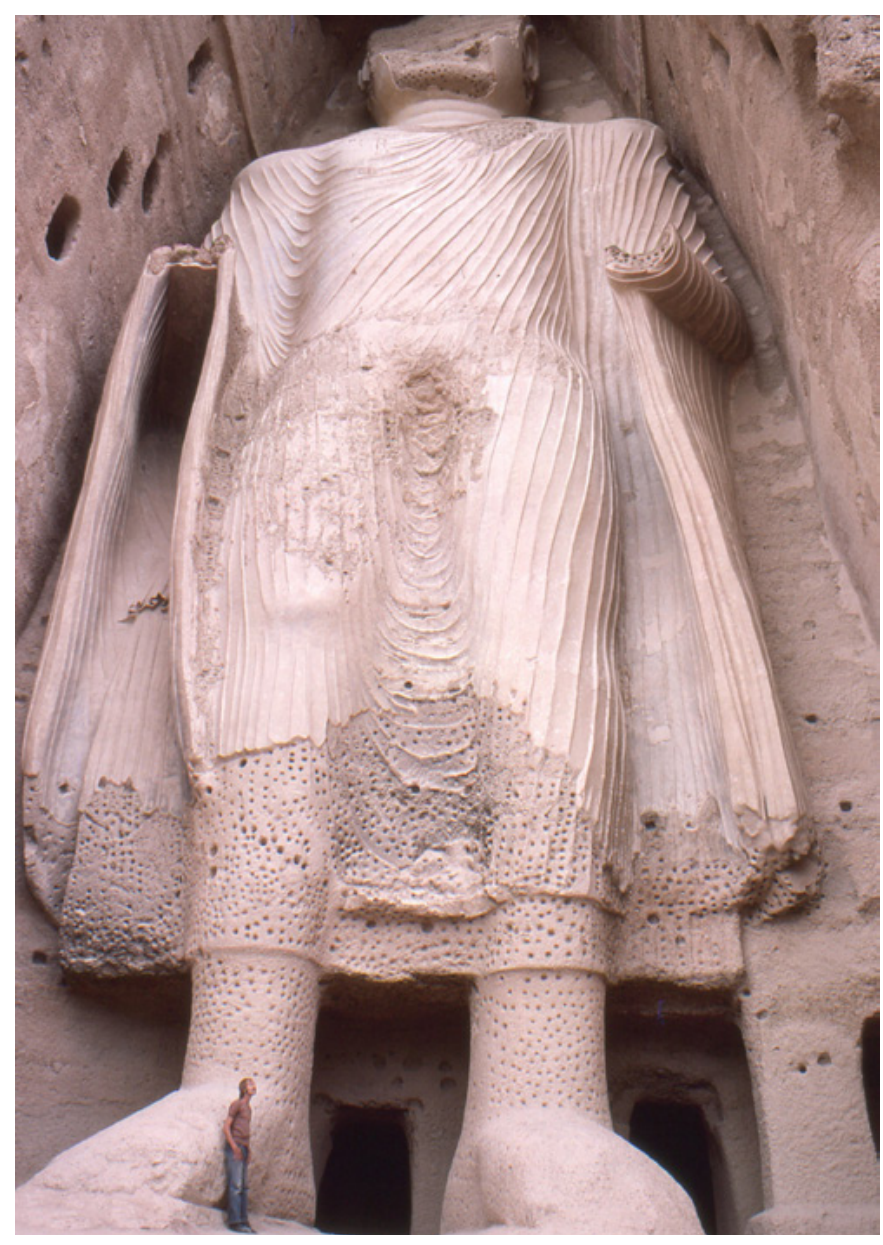

El buda más pequeño de Bamiyán, desde la base. Afganistán, 10 de agosto de 1977 | foto Phecda109

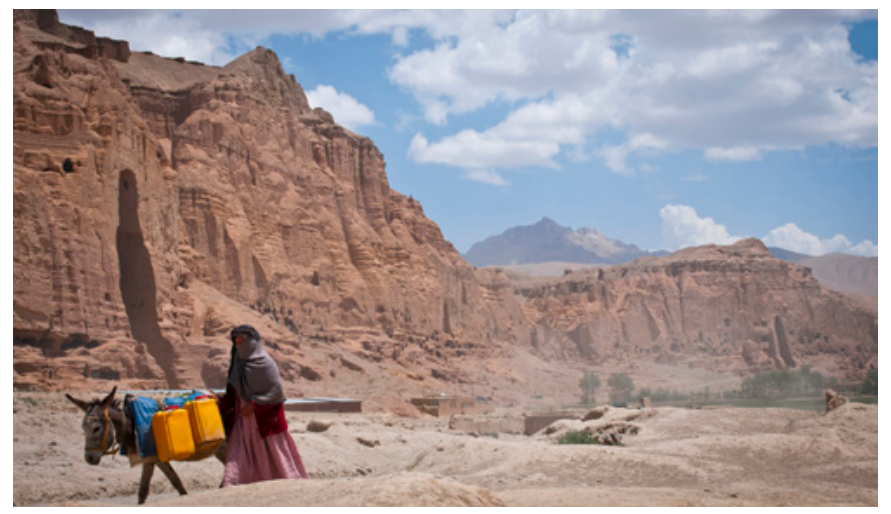

Una mujer pasea, en junio de 2012, por el lugar que ocupaban los Budas de Bamiyán hasta 2001 | foto Ken Scar monio excepcional que, tras haber sido tomado como objetivo de destrucción, debe convertirse en signo de concordia y reconocimiento, y en símbolo poderoso de una identidad plural cimentada en la confianza mutua".

El puente otomano de Móstar sobre el río Neretva (construido por los turcos en el siglo XVI y uno de los monumentos históricos más celebrados de esa ciudad herzegovina), que fue destruido en noviembre de 1993 por el Consejo Croata de Defensa, durante el conflicto étnico, fue reconstruido y entregado el 23 de julio de 2004, trabajado su rescate con fondos provenientes de la UNESCO, el Banco Mundial, las autoridades locales y otros países donantes. Un año después ingresó a la Lista del Patrimonio Mundial, como símbolo de la reconciliación nacional entre Bosnia y Herzegovina.

Fruto de la movilización internacional en contra de los actos de guerra en los Balcanes, el Tribunal Penal Internacional para la ex Yugoslavia (TPIY) condenó en 2004 a Miodrag Jokić, comandante de la Marina yugoslava, por la destrucción deliberada del patrimonio cultural en la ciudad vieja de Dubrovnik.

En otro extremo del mundo, no podemos olvidar las colosales estatuas de Buda, talladas en roca y estuco y situadas en acantilados y cuevas del valle de Bamiyán, en Afganistán central, durante los siglo $\mathrm{V}$ y $\mathrm{VI}$, parte de la ruta de la seda que unió a la India y China. Inscritas en la Lista del Patrimonio Mundial, desde 2001, a partir de su destrucción por parte del gobierno islamista talibán que las consideró como "ídolos" contrarios al Corán, se encuentran en la Lista del Patrimonio Mundial en Peligro. Los gobiernos de Alemania y Japón financian la reconstrucción parcial de las imágenes, bajo la coordinación del Consejo Internacional de Monumentos y Sitios (ICOMOS).

Ante el desenfrenado crecimiento de acciones bélicas a partir del decenio de 1980, primero en el Asia central (Afganistán) y luego en Europa (Bosnia y Herzegovina), la Conferencia General, durante los trabajos de su $32^{a}$ reunión, hizo pública la Declaración de la UNESCO rela- 
a debate Patrimonio, terrorismo y desastres naturales ¿Cómo prevenir y abordar los enormes daños al patrimonio cultural mundial?

| coordinan Francisco Javier López Morales, Francisco Vidargas

tiva a la destrucción intencional del patrimonio cultural, expresando "su profunda preocupación por el aumento del número de actos de destrucción intencional del patrimonio cultural", e instando a los Estados Miembros implicados en un conflicto armado, a "tomar todas las medidas oportunas para llevar a cabo sus actividades de manera que quede protegido el patrimonio cultural, de forma acorde con el derecho internacional consuetudinario y los principios y objetivos enunciados en los acuerdos internacionales y las recomendaciones de la UNESCO, referentes a la protección de dicho patrimonio durante las hostilidades."

Más recientemente, en el Sahel, durante la Rebelión Tuareg de 2012, asistimos a la demolición en la histórica región de Tombuctú (Malí) de mezquitas como la de Sidi Yahiya, los mausoleos -entre ellos los de Sidi Mahmud, Sidi Moctar, Alpha Moya, Sheij al Kebir y la Tumba de los Askia-, junto con otros edificios históricos, además de las bibliotecas que resguardaban innumerables manuscritos preislámicos y medievales, y en la que participaron organizaciones independentistas como el Movimiento Nacional para la Liberación del Azawad (MNLA) y grupos islamistas como Ansar Dine, Boko Haram y Al Qaeda en el Magreb Islámico (AQMI).

El Comité del Patrimonio Mundial, durante su 36ª sesión realizada en San Petersburgo, Federación de Rusia, inscribió a la Tumba de los Askia y los mausoleos en la Lista del Patrimonio Mundial en Peligro y se declaró públicamente contra su destrucción, calificándolo de "auténtico crimen contra la historia", instando a la comunidad internacional a "que no permitan que se borre de la faz de la Tierra estos monumentos históricos [...] uno de los lugares sagrados más antiguos de África." La Corte Penal Internacional (CPI) declaró el suceso como crimen de guerra, conforme al artículo 8 del Estatuto de Roma, que habla sobre "la destrucción y la apropiación de bienes, no justificadas por necesidades militares, y efectuadas a gran escala, ilícita y arbitrariamente", además de "dirigir intencionalmente ataques contra edificios dedicados a la religión, la educación, las artes, las ciencias o la beneficencia, los monumentos históricos..." (iv y ix).

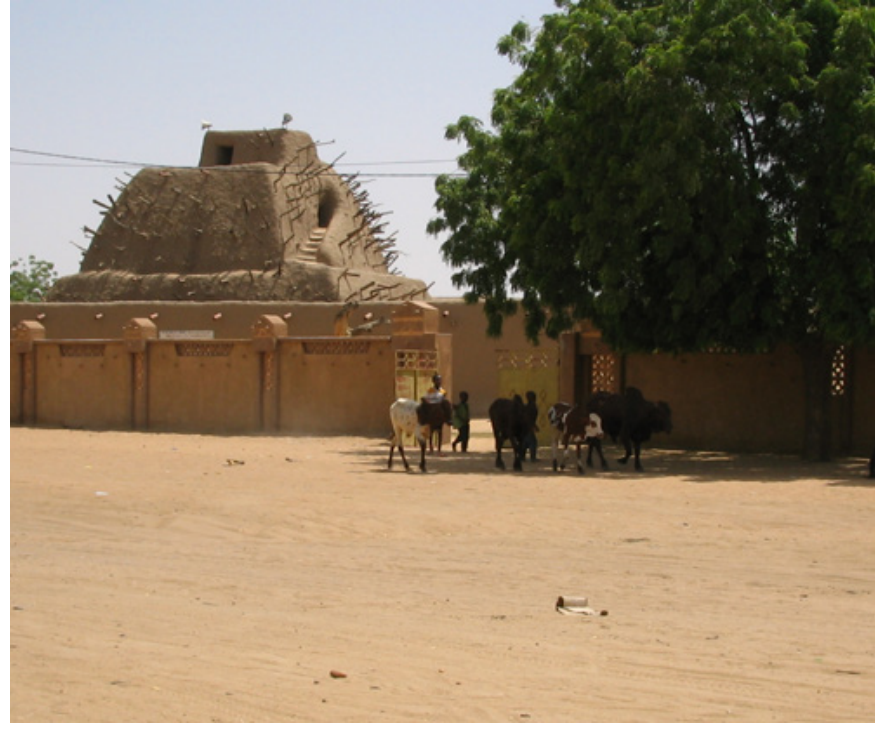

Tumba de los Askia en Gao (2006), antes de su destrucción | foto David Sessoms

En 2015 fueron reconstruidos bajo el patrocinio de la UNESCO y del gobierno de Francia. $Y$ en un hecho inédito, durante el primer juicio internacional dedicado a la destrucción del patrimonio cultural (2016), la Corte Penal Internacional declaró al yihadista Ahmad Al-Faqi Al-Mahdi, jefe de la Hesba (Ansar Dine), asociada con AQMI, culpable de crímenes de guerra y lo condenó a nueve años de prisión, por la destrucción deliberada en 2012 de diez mausoleos inscritos en la Lista del Patrimonio Mundial y de la llamada puerta "secreta" de la mezquita Sidi Yahiya, además de pagar 2,7 millones de euros a las víctimas por concepto de reparación.

2014 es el año que marca, para el Oriente Medio, el inicio de premeditados actos destructivos por parte del autodenominado Estado islámico del Iraq y el Levante (EIIL/ Daesh) en Iraq, Libia y la República Árabe Siria, calificados por Irina Bokova, Directora General y la Conferencia General de la UNESCO como "una forma de limpieza cultural" que "busca erradicar la diversidad cultural de una zona geográfica y suplantarla por una perspectiva cultural y religiosa única y homogénea." A su paso por los territorios, van destruyendo mezquitas chiitas como la de Al-Qubba Husseiniya, en Mosul, santuarios sunitas y sufíes, entre ellas las dl Ahmed al-Rifai y del Imam 


\begin{abstract}
a debate Patrimonio, terrorismo y desastres naturales ¿Cómo prevenir y abordar los enormes daños al patrimonio cultural mundial?
\end{abstract}

| coordinan Francisco Javier López Morales, Francisco Vidargas

Awnal-Din (del siglo XIII) y las tumbas de los profetas Daniel, Jonás y Jirjis; el memorial del genocidio armenio en Deir ez-Zor (Siria); las iglesias asirias cristianas y de Oriente en Tel Nasri, Tikrit y Mosul, además del histórico monasterio Mar Elián en Homs.

Además del saqueo y tráfico ilícito de piezas sustraídas de los sitios arqueológicos y museos, EIIL prosiguió con la detonación de sitios antiguos y medievales como la Pared de Nínive en Iraq, la ciudad asiria de Nimrud, Hatra y Palmira (Siria). Después de la destrucción el 4 de octubre de 2015 del Arco del Triunfo de Palmira y el atroz asesinato del antiguo jefe de arqueología del sitio, Khaled al-Asaad, la misma Bokova declaró que esos actos demuestran hasta qué punto "los extremistas quieren destruir esta diversidad y riqueza" y pidió a la comunidad internacional que "el Dáesh asesina a personas y destruye sitios pero no puede silenciar la historia y fracasará en su intento de borrar esta gran cultura de la memoria del mundo."

Desde Bagdad, después del saqueo del Museo de Mosul y la destrucción de Nimrud y Hatra, Bokova invitó al mundo a adoptar la campaña \#UnidosxEIPatrimonio, a fin de defender y proteger los valores del patrimonio cultural, cotrarrestando la propaganda del extremismo violento a través del uso de las redes sociales. A través del nuevo marco de acción de la UNESCO, llamado Empoderar a la juventud para construir la paz, se está aprovechando el potencial de las redes sociales para fortalecer el diálogo entre los jóvenes, conocer sus preocupaciones e ideas y ponerlas en práctica al servicio de la conservación del patrimonio, la diversidad culturales y la paz.

Las recientes resoluciones 2199 y 2347 , adoptadas por el Consejo de Seguridad de las Naciones Unidas, significan un mensaje contundente para el orbe, respecto a la indisociable vinculación entre la protección de la vida humana y el resguardo y conservación del patrimonio cultural.

La primera fue adoptada por 50 países en 2015, a fin de impedir el comercio de bienes culturales procedentes de Iraq y Siria, condenando "la destrucción del patrimonio cultural en el Iraq y la República Árabe Siria [...] con independencia de que tal destrucción sea accidental o deliberada, incluida la destrucción selectiva de lugares y objetos de importancia religiosa." Asimismo decidió que todos los Estados Miembros "adopten las medidas que correspondan para impedir el comercio de bienes culturales y otros artículos iraquíes o sirios de valor científico especial o importancia arqueológica, histórica, cultural y religiosa [...] incluso prohibiendo el comercio transfronterizo de esos artículos, para posibilitar su retorno seguro."

La segunda, sobre la protección del patrimonio cultural en peligro, adoptada apenas en marzo de 2017, se centró exclusivamente en el patrimonio cultural. Puso en relieve que "la destrucción ilícita del patrimonio cultural, así como el saqueo y el contrabando de bienes culturales en caso de conflicto armado [...] puede alimentar y exacerbar los conflictos y obstaculizar la reconciliación nacional después de los conflictos."

Asimismo, atendiendo a las conclusiones de la Conferencia Internacional sobre la Protección del Patrimonio Cultural en Zonas de Conflicto (2016), hizo suyos dos objetivos: la creación de un fondo internacional y de una red de "países seguros" para albergar los bienes culturales amenazados, teniendo en cuenta que el financiamiento de grupos terroristas a través del tráfico de bienes culturales está vinculado también con el crimen organizado.

Paralelamente, en estos años recientes, se dieron a conocer documentos e iniciativas internacionales de relevancia: en primer lugar, durante los trabajos de la sesión 39a del Comité del Patrimonio Mundial, Ilevada a cabo en Bonn, Alemania, el gobierno anfitrión impulsó la Declaración de Bonn sobre el patrimonio mundial que promueve a través de 32 articulados, "el fortalecimiento de la cooperación intergubernamental y su colaboración en la aplicación de las leyes sobre la protección y la conservación del patrimonio cultural, así como a reforzar la participación activa de todos los interesados, en particular aquellos en los dominios del arte y la cultura, a fin de implementar las medidas necesarias para el com- 
a debate Patrimonio, terrorismo y desastres naturales ¿Cómo prevenir y abordar los enormes daños al patrimonio cultural mundial?

| coordinan Francisco Javier López Morales, Francisco Vidargas

bate al tráfico de bienes culturales en todas sus formas y aspectos."

Concluye exhortando a fortalecer la protección internacional del patrimonio cultural y natural, "contribuyendo activamente en la Coalición mundial lanzada por la Directora General de la UNESCO, reconociendo que la construcción de la paz de mañana, necesita la defensa, hoy, de nuestro común patrimonio, así como de la diversidad y la tolerancia."

Impulsada por los gobiernos de Francia y de los Emiratos Árabes Unidos, en diciembre de 2016 se llevó a cabo en Abu Dhabi la Conferencia Internacional sobre la Protección del Patrimonio Cultural en Zonas de Conflicto, en la que 40 países adoptaron la Declaración de Abu Dhabi, que se comprometió a perseguir tres objetivos ambiciosos y perennes para garantizar la movilización de la comunidad internacional, en favor de la preservación del patrimonio: "la constitución de un fondo internacional para la protección del patrimonio cultural en peligro, en periodo de conflicto armado, que permita financiar acciones de prevención y/o de urgencia, luchar contra el tráfico ilícito de bienes culturales así como participar en la restauración de bienes culturales dañados" y la "creación de una red internacional de refugios para proteger de forma temporal los bienes culturales en peligro, a causa de conflictos armados o terrorismo, en su territorio", además de una declaración política común, destinada a alentar la adopción de una resolución marco sobre la protección del patrimonio en peligro, en el Consejo de Seguridad de las Naciones Unidas, que fructificó tres meses después.

Durante los trabajos de redacción de dicho documento, México insistió respecto a los "países refugio", que se tomaran en cuenta las características nacionales y regionales, así como el contexto de los bienes culturales a proteger, a fin de evitar un mayor daño a los mismos.

Como resultado de esa reunión, en marzo de 2017 (Museo del Louvre), se constituyó la Fundación Alianza Internacional para la Protección del Patrimonio en las
Zonas de Conflicto (ALIPH), en materia de protección del patrimonio en peligro, coincidiendo con los objetivos de la UNESCO, conforme a la Estrategia aprobada por la Conferencia General en 2015 (Resolución $38 \mathrm{C} / 49)$.

\section{Los desastres naturales}

Las recientes discusiones en el interior de la propia UNESCO nos dan pauta para abordar el otro tema motivo de este debate: la conservación del patrimonio cultural frente a los desastres naturales.

Al respecto, resulta interesante hacer una breve revisión de los documentos y acciones emanados desde el seno del organismo de las Naciones Unidas.

Como señaló Gustavo Araoz, hasta hace poco presidente de ICOMOS, los desastres naturales continuarán produciéndose con mayor frecuencia, debido al cambio climático. Por ello, aunque es poco lo que podemos hacer frente a dichos acontecimientos y para su prevención, "se debe fomentar el desarrollo de mejores planes de preparación para desastres" que a la par aumenten la resistencia de los monumentos y los sitios a la actividad sísmica, a los vientos e inundaciones.

Por su parte, Francesco Bandarin, anterior director del Centro del Patrimonio Mundial, advierte que la mayoría de las catástrofes "son efectos combinados de peligros y de vulnerabilidades resultado de la compleja interacción entre numerosos factores, la mayoría dependiendo del control humano". Y subraya que "los efectos de un solo desastre en los bienes culturales y naturales, suelen superar con creces el deterioro causado por el desgaste paulatino, a largo plazo y, en algunas ocasiones, puede llevar a su completa desaparición."

Ante los recientes desastres naturales suscitados en la última década en Iberoamérica, ha quedado más en evidencia la necesidad de que los principios de la conservación preventiva deben estar incluidos en los instrumentos jurídicos y normativos, para poder dar respuestas integradas a las necesidades de reconstrucción, posteriores 


\begin{abstract}
a debate Patrimonio, terrorismo y desastres naturales ¿Cómo prevenir y abordar los enormes daños al patrimonio cultural mundial?
\end{abstract}

| coordinan Francisco Javier López Morales, Francisco Vidargas
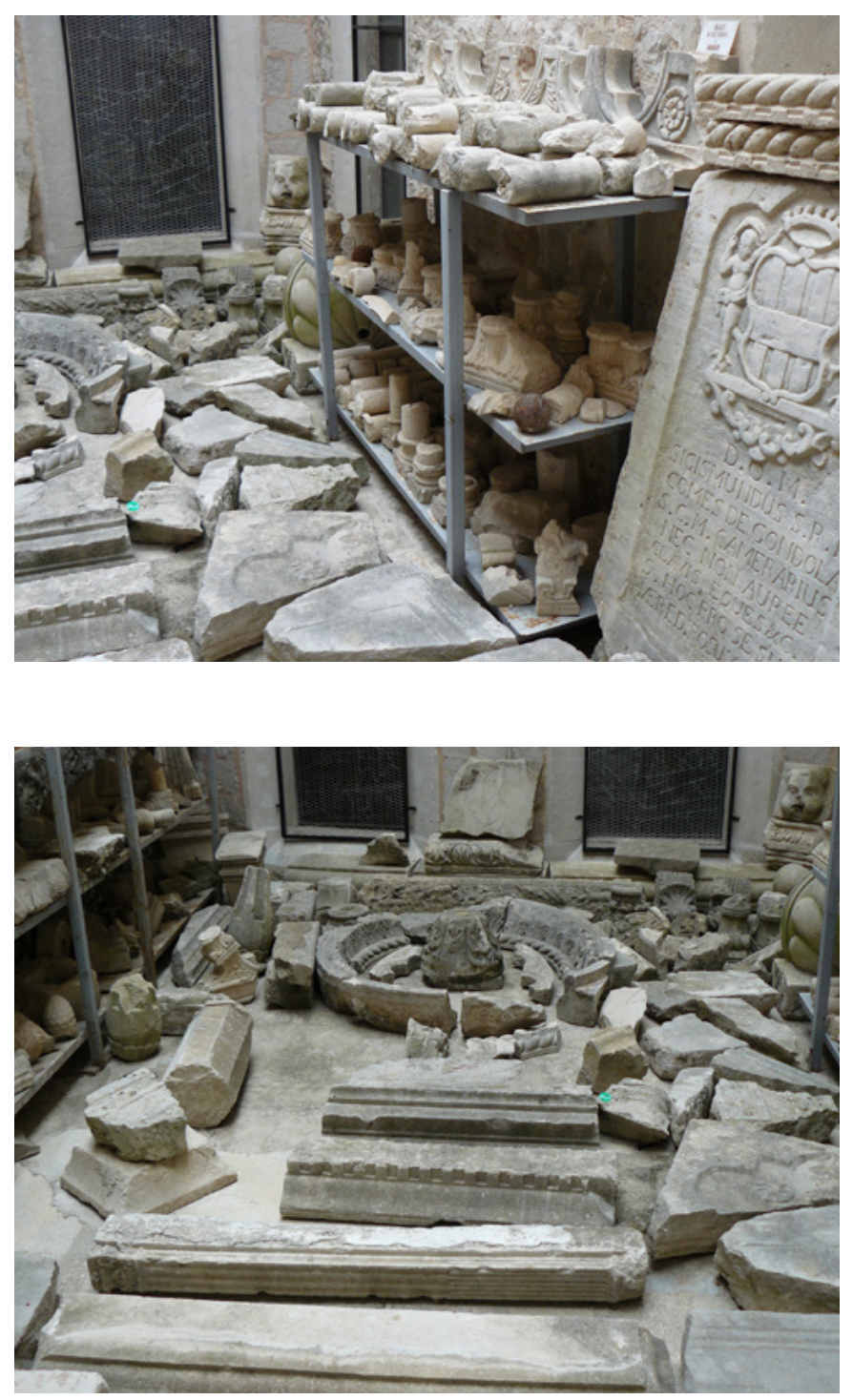

Restos arquitectónicos de la guerra de los Balcanes, Dubrovnik (Hrvatska/ Croacia). Fotografías tomadas el 8 de enero de 2007 | fotos Álvaro Herraiz San Martín

a las emergencias. Asimismo, se deben contar con planes para la reparación o reconstrucción de las estructuras dañadas.

Los expertos del Comité Científico del ICOMOS para el Análisis y Restauración de las Estructuras del Patrimonio Arquitectónico redactaron en 1998 la Declaración de
Asís, que contempla entre sus acciones de respuesta urgente medidas de mitigación basadas en una equilibrada valoración, para evitar alteraciones en la concepción original, en la técnica y la tecnología, así como para proveer el nivel de seguridad requerido. Debe darse prioridad a medidas compatibles y reversibles.

El artículo 5 del Segundo Protocolo (1999) de la Convención para la Protección de los Bienes Culturales en caso de Conflicto Armado (1954) habla de medidas preparatorias como "la preparación de inventarios, la planificación de medidas de emergencia para la protección contra incendios o el derrumbamiento de estructuras, la preparación del traslado de bienes culturales muebles o el suministro de una protección adecuada in situ de esos bienes". Esto abrió la puerta para que, a través del Comité del Escudo Azul, se pudiera incluir a los desastres naturales en sus acciones.

El Escudo Azul internacional, entre sus objetivos para la protección del patrimonio cultural, contempla "la protección de los bienes culturales en caso de grandes catástrofes", así como la preparación para emergencias y "la coordinación del desarrollo de capacidades nacionales [...] en las áreas de preparación y respuesta contra desastres naturales y causados por el hombre."

A partir de la Declaración de Seúl sobre la protección del patrimonio cultural en situaciones de emergencia (2011), se hace hincapié en los daños al acervo patrimonial, provocados por la degradación medioambiental y los cambios climáticos. El documento elaborado por el Comité Internacional del Escudo Azul propone "la posibilidad de establecer un fondo "de auxilio cultural inmediato en situaciones de emergencia", además de ser "el punto focal en la coordinación de rescate y socorro a nivel internacional cuando el patrimonio cultural esté en peligro debido a catástrofes naturales."

La División de Patrimonio del Sector Cultura de la UNESCO, como parte de la Estrategia para reforzar la labor de la UNESCO en materia de protección de la cultura y promoción del pluralismo cultural en caso de con- 
a debate Patrimonio, terrorismo y desastres naturales ¿Cómo prevenir y abordar los enormes daños al patrimonio cultural mundial?

| coordinan Francisco Javier López Morales, Francisco Vidargas

flicto armado, creó en 2014 a la Unidad de Preparación y Respuesta ante Emergencias, junto con un Fondo de Emergencia del Patrimonio que depende, principalmente, de fondos extrapresupuestarios. En el marco del Gran Programa IV de la UNESCO, dicho fondo se contempla como parte del "desarrollo de una aplicación transversal de las convenciones, para impulsar respuestas más integradas y coordinadas."

Asimismo, la UNESCO pretende fortalecer su función en situaciones de emergencia, conflicto o desastre, mediante "los mecanismos de preparación para casos de desastre y de respuesta ante los mismos acordados en el plano internacional", como el Marco de Sendai para la Reducción del Riesgo de Desastres 2015-2030 (2015), el Acuerdo de París sobre el cambio climático (2015) y la Agenda 2030 y los Objetivos de Desarrollo Sostenible (2016), contribuyendo a "impulsar una respuesta más coordinada e integrada a través de las convenciones."

La reunión internacional que organizó la Dirección de Patrimonio Mundial en México, sobre las Convenciones UNESCO (2013), nos permitió constatar que si bien el mandato del organismo internacional puede ser considerado, en muchos casos, como idealista, lo cierto es que el idealismo y el pragmatismo no son necesariamente conceptos opuestos entre sí, como tampoco lo son los intereses y los principios morales.

La trama y el tejido de las sociedades son frágiles y muy fáciles de desgarrar. Repararlos y restaurarlos es complicado y tardan mucho en sanar, más aún cuando la persecusión y la destrucción deliberada del patrimonio cultural es utilizada como instrumento de guerra, como hemos visto en el caso de los Balcanes y en Oriente Medio. Cualquier ataque a la cultura en uno de sus Estados Miembros es un ataque a la cultura de todos, como quedó plasmado en la cimientos de la Convención sobre la protección del Patrimonio Mundial, Cultural y Natural de 1972.

Precisamente es a la UNESCO que la comunidad internacional ha encomendado la tarea primordial de erra- dicar de las sociedades la agresión y la guerra, para forjar en su lugar una paz que no esté basada, exclusivamente, en mecanismos políticos y económicos. La verdadera paz debe estar fincada en la solidaridad intelectual y moral de la humanidad, tal y como se declara en los textos fundacionales de la propia UNESCO.

Es necesario convencernos de que la UNESCO, a través de sus convenciones culturales y su espíritu de paz, es el marco adecuado para la acción nacional y la cooperación internacional frente a la sobreexplotación, los desastres naturales, los cambios climáticos, los irracionales actos terroristas y los fraticidas conflictos armados. Con ella, a la par de los instrumentos legales y los normativos, es que podremos proteger a la cultura y al patrimonio cultural frente a los desafíos y las amenazas de un mundo efervescente, convulso y necesitado de tolerancia. 